\title{
The Ameliorating Effect of Chloroform and Aqueous Ethanol Extracts from Pleurotus tuber reguim (Fr.) Sing. (Pleurotaceae) sclerotia on Triton-X Induced Hyperlipidemia in Wistar Rats
}

Ezea $\mathrm{BO}^{1}$, Afieroho $\mathrm{OE}^{1^{*}}$, Suleiman M, Aprioku $\mathrm{JS}^{2}$, Abo KA ${ }^{1}$

${ }^{1}$ Department of Pharmacognosy and Phytotherapy, University of Port Harcourt, Nigeria

${ }^{2}$ Department of Experimental Pharmacology and Toxicology, University of Port Harcourt, Nigeria

DOI: $10.36348 /$ sijtcm.2021.v04i04.001 $\quad$ | Received: 27.01.2021 | Accepted: 16.02.2021 | Published: 07.04 .2021

*Corresponding author: Afieroho $\mathrm{OE}$

\section{Abstract}

This report validates the anti-hyperlipidemic property of Pleurotus tuber reguim an edible mushroom widely used for weight loss among other ailments, using Triton X-100 induced hyperlipidemic rats. The lipophilic chloroform (CHE) and hydrophilic $70 \%$ aqueous ethanol (AQE) extracts were obtained by successive cold maceration in increasing order of solvent polarity. Anti-hyperlipidemic activities of the extracts at 100 and $200 \mathrm{mg} / \mathrm{kg}$ body weight, was evaluated using Triton X-100 induced hyperlipidemic rats. Artovastatin was used as the standard drug. Compared to the hyperlipidemic untreated control group, there was a significant $(\mathrm{p}<0.05)$ dose dependent reduction in the plasma total cholesterol (TC), triglyceride (TG), very low density lipoprotein (VLDL), low density lipoprotein (LDL), and increase in the high density lipoprotein (HDL) after 7 days treatment with the extracts. The trend in the ameliorative activities of the extracts and atovastatin were in the following rank order: atovastatin (43.5\%)>CHE-200mg/kgbw (41.4\%)>CHE$100 \mathrm{mg} / \mathrm{kgbw}(38.4 \%>\mathrm{AQE}-200 \mathrm{mg} / \mathrm{kgbw}(35.9 \%)>\mathrm{AQE}-100 \mathrm{mg} / \mathrm{kgbw}(27.6 \%)$ for TC; atovastatin $(73.5 \%)>\mathrm{CHE}-$ $200 \mathrm{mg} / \mathrm{kgbw}(68.0 \%)>\mathrm{CHE}-100 \mathrm{mg} / \mathrm{kgbw}(64.5 \%>\mathrm{AQE}-200 \mathrm{mg} / \mathrm{kgbw}(62.3 \%)>\mathrm{AQE}-100 \mathrm{mg} / \mathrm{kgbw}(62.2 \%)$ for TG; CHE-200mg/kgbw (114.4 \%)> AQE-200mg/kgbw(87.3\%) >atovastatin (68.7\%)>CHE-100mg/kgbw (38.5\%)>AQE$100 \mathrm{mg} / \mathrm{kgbw}(8.8 \%)$ for HDL; atovastatin $(73.5 \%)>\mathrm{CHE}-200 \mathrm{mg} / \mathrm{kgbw}(68.0 \%)>\mathrm{CHE}-100 \mathrm{mg} / \mathrm{kgbw}(64.5 \%>\mathrm{AQE}-200$ $\mathrm{mg} / \mathrm{kgbw}(62.3 \%)>\mathrm{AQE}-100 \mathrm{mg} / \mathrm{kgbw}(62.2 \%)$ for $\mathrm{VLDL}$; and CHE-200mg/kgbw (78.5\%) > atovastatin $(66.8 \%)>$ AQE-200mg/kgbw (63.5\%)>AQE-100mg/kgbw(26.8\%) for LDL. Triterpenoids (phytosteroids), fatty acids, and cardenolides are present in the CHE while, amino acids, saponins and carbohydrate were present in the AQE as metabolites with alkaloids and anthraquinones were absent. $P$ tuber reguim possesses anti-hyperlipidemic effects which could be due to the phyto-constituents present thus justifying its traditional use for weight loss.

Keywords: Pleurotus tuber reguim, dyslipidemia, cardiovascular health, nutraceuticals.

Copyright (C) 2021 The Author(s): This is an open-access article distributed under the terms of the Creative Commons Attribution 4.0 International License (CC BY-NC 4.0) which permits unrestricted use, distribution, and reproduction in any medium for non-commercial use provided the original author and source are credited.

\section{INTRODUCTION}

Hyperlipidemia assists significantly in the development of atherosclerosis and coronary hearts disease. Atherosclerosis and related coronary heart diseases are among the most common causes of mortality and morbidity worldwide. They are responsible each year for $30 \%$ of mortality in the world [1]. Hyperlipidemia is a condition in which there is abnormal high levels of lipids in serum largely cholesterol and triglyceride [2]. These lipids are transported in the blood as part of large molecules called lipoproteins, and the density of the lipids and the type of protein determines the fate of the particle and its influence on metabolism [2,3]. They are either low density lipoprotein (LDL), or high density lipoprotein(HDL) [4] of which the LDL when elevated, pre-dispose one to cardiovascular ailments unlike the HDL. Hyperlipidaemia leads to various cardiovascular disorders like angina pectoris, myocardial infarction, hypertension, atherosclerosis, and congestive heart failure [5]. Treatment of hyperlipdaemia is geared towards a reduction in the elevated LDL, triglyceride (TG) and total cholesterol (TC), alongside an enhancement in the diminished HDL values since hyperlipidemia is usually an elevated level of TC,TG and LDL, and decreased level of HDL $[6,7]$. The major side effects of anti-hyperlipidemic agents include muscle toxicity, rhabdomyolysis, and psychiatric adverse reactions which include depression, memory loss, confusion and aggressive reactions $[5,8,9]$. These drawbacks have made researchers to continue in the search for safer and effective anti-hyperlidaemic agents 
that could be developed into clinically useful drugs. Recourse to botanical derived bioactive metabolites have continued to drive this strata of the drug discovery pipeline. The edible mushroom species Pleurotus tuber reguim (Fr.) Sing. is found in tropical and sub-tropical regions of the World [10]. It is an edible mushroom that produces the edible sclerotia or underground tubers as well as fruit bodies belonging to the family Pleurotaceae. Several pharmacological properties have been reported for extracts of Pleurotus species such as antigenotoxic, bioantimutagenic [11], antiinflammatory, anti-hyperlipidemic, antihypertensive, and antihyperglycaemic [12] antibacterial and antifungal [13] activities. There is also research evidence that extracts from medicinal mushrooms can function as immune-modulators [14]. The folklore use of Pleurotus tuber-reguim in Nigeria against weight loss reduction has been documented [15]. This present study is hence aimed at validating the antihyperlipidemic activities of the chloroform (non-polar) and aqueous ethanol (polar) extracts of the sclerotia of Pleurotus tuber reguim using Triton X-100 induced hyperlipidemic rats as a preliminary step towards the isolation of the anti-hyperlipidemic constituents from this edible mushroom acclaimed for weight loss and the treatment of heart ailments.Triton $\mathrm{x}-100$ is a non-ionic detergent that causes an increment of total cholesterol and triglycerides in the blood altering hepatic lipid metabolism [16]. It has been widely used in in vivo studies to produce acute hyperlipidemia in animal models in order to study the lipid-lowering effect of natural or synthetic drugs [17]. Triton $\mathrm{x}-100$ has been found to prevent the catabolism of triglycerol-rich lipoprotein by lipoprotein lipase [18].

\section{MATERIAL AND METHODS \\ Sample Collection and Identification}

Pleurotus tuber reguim sclerotia was purchased from Oil Mill Market, Port-Harcourt, Rivers State, Southern Nigeria and authenticated by a Mycologist at the International Centre for Ethnomedicine and Drug Development, Nsukka, Nigeria with Voucher specimen number: Inter CEDD/971.

\section{Chemicals/Drugs/Reagents}

Analytical grade chemicals (Merck, Germany) which includes absolute ethanol, and chloroform were used. Others include: Triton X-100 (Sigma-Aldrich, Germany), Atorvastatin, and distilled water,

\footnotetext{
Animals

One hundred and twenty (120) Wistar rats 170- 200g were used for the study. The rats were purchased from the Faculty of Pharmaceutical Sciences animal house, University of Port-Harcourt. The animals were provided ad libitum access to tap water throughout the experimental duration and maintained in a 12 hours light-dark cycle under standard laboratory conditions $\left(22 \pm 2{ }^{\circ} \mathrm{C}\right)$. All experiments were approved by the
}

Research Ethics Committee of the University of Port Harcourt, Nigeria (approval Ref No: UPH/CEREMADREC/MM67/016).

\section{Extraction Method}

Chloroform (CHE) and $70 \%$ aqueous ethanol (AQE) extracts of Pleurotus tuber regium were obtained by successive cold maceration in order of solvent polarity. Briefly, The sample (10 kg) was first extracted by cold maceration in chloroform as solvent for three consecutive days each with agitation at interval of 6hrs and fresh replacement of solvent every $24 \mathrm{hrs}$. The combined chloroform filtrate was, after concentration using a rotary evaporator and drying, kept as the chloroform (non-polar) extract CHE. The marc obtained after extraction with chloroform was then further extracted with $70 \%$ aqueous ethanol in a similar manner and the aqueous ethanol extracts obtained were pooled together, concentrated using a rotary evaporator and further dried in a vacuum desiccator to obtain the aqueous ethanol (Polar) extract (AQE). The CHE and AQE were used for the study.

\section{Acute Toxicity}

This was done using the method reported by Lorke [19] using Wistar albino rats. Briefly, A total of eighteen (18) Wistar albino rats selected for this studies were divided into six groups of three animals each. The animals were fasted overnight before oral administration of the extract. The first three groups were treated with 10,100 , and $1000 \mathrm{mg} / \mathrm{kg}$ body weight of the extract. The animals were kept under observation for 24 hours for signs of toxicity and death. After 24 hours, none of the animals died or adverse effect was recorded. Then the remaining three groups of the animals were given doses of the extract at 1600, 2900, and $5000 \mathrm{mg} / \mathrm{kg}$, respectively and observed for further 24 hours.

\section{Induction of Hyperlipidemia}

Acute hyperlipidemia was induced in animals by intraperitoneal administration of Triton X-100 (Tyloxapol, Sigma-Aldrich) to the rats at a dose of 150 $\mathrm{mg} / \mathrm{kg}$ body weight. Induced rats were allowed to stabilize for 72 hours before commencing treatment.

\section{Antihyperlipidemic Assay}

The extracts were evaluated for in vivo antihyperlipidemic activities using method described by Kothiyal and Gupta[20] with modification. The study was carried out in the animal house of Faculty of Pharmaceutical Sciences, University of Port Harcourt. Briefly, Thirty Wistar rats were randonmnly divided into seven groups each having 5 animals each (A-G). Group A was not given any treatment (normal control group), while the other six groups (B-G) were treated with single dose triton $\mathrm{X}-100(150 \mathrm{mg} / \mathrm{kg}$ bw, ip) to induce hyperlipidemia. After hyperlipidemia induction, group B received no other treatment (hyperlipidemic untreated coontrol group), while group $\mathrm{C}$ received 
standard antilipidemic drug atorvastatin $(10 \mathrm{mg} / \mathrm{kgbw}$, orally, groups D and E received 200 and $100 \mathrm{mg} / \mathrm{kgbw}$ AQE orally, respectively, and groups $F$ and $G$ were administered 100 and $200 \mathrm{mg} / \mathrm{kgbw}$ CHE orally, respectively. The agents were administered daily for 7 days. On the $8^{\text {th }}$ day after the treatment, blood samples were collected by retro-orbital puncture in dry EDTA bottles and the serum lipid levels; total cholesterol (TC), triglycerides (TG), high density lipoprotein (HDL), low density lipoprotein (LDL), and very low density lipoprotein (VLDL) were determined using standard methods with commercially available kits.

\section{Phytochemical Screening}

This was done using standard phytochemical screening methods [21, 22].

\section{Data presentation and Statistical Analysis}

All data were expressed as mean \pm SEM. One way analysis of variance (ANOVA) and student's t-test were used to analyze the data and test for significance between experimental and control groups ( $\mathrm{p}$ values < 0.05 were considered significant).

\section{RESULTS AND DISCUSSION}

The extracts of $P$. tuber reguim were found to be safe at $5000 \mathrm{mg} / \mathrm{kg}$ bw as there were neither deaths nor observed visible signs of toxicity in all the doses that were used in the $\mathrm{LD}_{50}$ study. TC, TG, LDL, and VLDL levels were significantly $(\mathrm{p}<0.05)$ increased, while HDL was significantly $(\mathrm{p}<0.05)$ decreased in the hyperlipidemic untreated control group compared to the normal control group (Table-1). Hyperlipidemic groups treated with Atorvastatin $(10 \mathrm{mg} / \mathrm{kg})$, chloroform, CHE $(100,200 \mathrm{mg} / \mathrm{kg})$ or aqueous ethanol, AQE $(100,200$ $\mathrm{mg} / \mathrm{kg}$ ) extracts of Pleurotus tuber reguim showed significant $(\mathrm{p}<0.05)$ ameliorating effect on Triton-Xinduced hyperlipidemia by decreasing the elevated levels of TC, TG, LDL, and VLDL in hyperlipidemic untreated control group, and increasing the reduced levels of HDL (Table-1). There was significant and dose-dependent decrease in TC level in AQE, CHE, and atorvastatin treated groups compared to hyperlipidemic control group. Also, except for the group that received $100 \mathrm{mg} / \mathrm{kg}$ bw of AQE, where the observed TC value remained significantly increased, all other extract and atorvastatin treated groups were not significantly different when compared with the normal control group (Table-1). Also, except for the group that received 100 $\mathrm{mg} / \mathrm{kg}$ bw of AQE, where the observed TC value remained significantly increased, all other extract and atorvastatin treated groups were not significantly different when compared with the normal control group (Table-1). When atorvastatin was compared with extract groups, only the low dose AQE (100 mg/kg) group showed significant difference with higher TC level than atorvastatin (Table-1). The trend in the rank for TC was observed to be: atovastatin (43.5\%)>CHE$200 \mathrm{mg} / \mathrm{kgbw}(41.4 \%)>\mathrm{CHE}-100 \mathrm{mg} / \mathrm{kgbw}(38.4 \%>\mathrm{AQE}$ $-200 \mathrm{mg} / \mathrm{kgbw}(35.9 \%)>\mathrm{AQE}-100 \mathrm{mg} / \mathrm{kgbw}(27.6 \%)$.
Thus it could be inferred that the lipophillic extract(CHE) showed a better ameliorating effect on the TC elevation compared to the hydrophilic AQE.

\section{Amelioriating effect on Total triglyceride (TG)}

There is a significant $(\mathrm{p}<0.05)$ reduction in TG level in extract and atorvastatin treated groups compared to the hyperlipidemic untreated control (Table 1).The observed TG values of the exracts and atorvastatin hyperlipidemic treated groups were not significantly different $(\mathrm{p}>0.05)$ compared to that of the normal control group. Similar to TC result, the ameliorative effects on TG were dose dependent with the non-polar CHE exhibiting a better (though not significant $(p>0.05)$ effect compared to the polar AQE. The rank order of ameliorative effect on TG elevation by the agents was: atovastatin $(73.5 \%)>\mathrm{CHE}$ $200 \mathrm{mg} / \mathrm{kgbw}(68.0 \%)>\mathrm{CHE}-100 \mathrm{mg} / \mathrm{kgbw}(64.5 \%>\mathrm{AQE}$ $-200 \mathrm{mg} / \mathrm{kgbw}(62.3 \%)>\mathrm{AQE}-100 \mathrm{mg} / \mathrm{kgbw}$ (62.2\%).

\section{Amelioriating effect on High Density Lipoproteins (HDL)- cholesterol}

At the different dose levesls, the non polar CHE increased HDL level more than the polar AQE, and HDL levels in $200 \mathrm{mg} / \mathrm{kg}$ bw AQE or CHE groups were higher compared to the atorvastatin, although values were not significant (Table-1). The general trend in the calculated ameliorating effect for HDLccholesterol was observed to be: CHE-200mg/kgbw $(114.4 \%)>$ AQE-200mg/kgbw $(87.3 \%)$ >atovastatin $(68.7 \%)>\mathrm{CHE}-100 \mathrm{mg} / \mathrm{kgbw} \quad(38.5 \%)>\mathrm{AQE}-100 \mathrm{mg} /$ $\operatorname{kgbw}(8.8 \%)$. The effects of HDL is to make the transportation of cholesterol easy from peripheral tissues such as arteries to the liver for catabolism [23]. This results in the reduction of cholesterol and triglycerides and hence a reduction in cardiovascular risk. HDL has been recognised as the protective cholesterol fraction because there is an inverse relationship between the concentration of HDLcholesterol and the agent of cardiovascular complications.

\section{Amelioriating effect on Very Low Density Lipoproteins (VLDL)- cholesterol}

VLDL is a proportion of the TG and its plasma elevation just like TC and TG, is a risk factor in the progression of arteriosclerosis, and related cardiovascular diseases. In this investigation, the elevated VLDL cholesterol peaked in the hyperlipidemic untreated controls group and for the hyperlipidemic groups treated with the various doses of the test extracts and atorvastatin, there was a significant $(p<0.05)$ amelioration effect. Just as observed for the other parameters, the CHE extract showed relatively better reduction in VLDL-cholesterol compared to the AQE though not significant ( $p>0.05$ ). The ranked order in ameliotation of the elevated VLDL-cholesterol was observed to be: atovastatin $(73.5 \%)>\mathrm{CHE}-200 \mathrm{mg} / \mathrm{kgbw}$ $(68.0 \%)>\mathrm{CHE}-100 \mathrm{mg} / \mathrm{kgbw}(64.5 \%>\mathrm{AQE}-200$ $\mathrm{mg} / \mathrm{kgbw}(62.3 \%)>\mathrm{AQE}-100 \mathrm{mg} / \mathrm{kgbw}(62.2 \%)$. 


\section{Amelioriating effect on Low Density Lipoproteins (LDL)- cholesterol}

Unlike HDL-cholesterol which is good, elevated LDL- cholesterol is a risk to cardiovascular health. From the result, the elevation of LDLcholesterol seen in the hyperlipidemic untreated group was significantly $(p<0.05)$ reduced in a dose dependent manner after the 7 days treatment with the CHE and AQE extracts as well as the standard drug atorvastatin. Just as observed for the other parameters, the non-polar CHE extract showed a better (though not significant $p>$ $0.05)$ ameliorating effect compared to the polar AQE extract.The general trend in the calculated ameliotating effect for LDL-cholesterol was observed to be: CHE$200 \mathrm{mg} / \mathrm{kgbw}(78.5 \%)>$ atovastatin $(66.8 \%)>\mathrm{AQE}-$ $200 \mathrm{mg} / \mathrm{kgbw}(63.5 \%)>\mathrm{AQE}-100 \mathrm{mg} / \mathrm{kgbw}(26.8 \%)$.

\section{Phytochemical Screening}

The result of the phytochemical screening showed the presence of triterpenoids, saponins, cardenolide, amino acids, fatty acids and carbohydrates derivatives with the absence of phenolics, alkaloids and anthraquinones. Whereas the non-polar CHE is found to contain triterpenoids (phytosteroids), fatty acids and cardenolide, the polar AQE was amino acids, saponins and carbohydrate.In an earlier phytochemical study
[24], erogosterol and poly-unsaturated fatty acids derivatives have been characterized from this mushroom using Gas-Chromatography-Mass Spectrometry techniques. Ergosterol derivatives and related phytosterols have been reported to be antihyperlipidemic $[12,25,26]$. Poly unsaturated fatty acids such as the omega- 3 derivatives are also good in the management of obesity and cardiovascular ailments unlike the saturated fatty acids. Essential amino acids like methionone, threonine and tryptophan have also been found to reduce cholesterol level and prevent fatty liver [27]. Saponins have been reported to act as cholesterol reduction agents by binding with cholesterol in the intestinal lumen [28] and also as surface active/ fat emulsifying agents. Water soluble polysaccharides such as Lecithin found in mushrooms have been reported to play a major role in the incorporation of free cholesterol in HDL and VLDL which turn them back to the liver cells for catabolism [20]. The observed antihyperlpidemic activity of the extracts from the sclerotia of this edible mushroom P. tuber reguim could therefore be attributed to the presence of one or more of these phytochemical. The lower potency and ameliorative effect of AQE compared to CHE might be due to difference in polarity and bioactive phytochemicals present in the extracts.

Table-1: Anti-hyperlipidemic parameters results

\begin{tabular}{|c|c|c|c|c|c|}
\hline Test groups & TC (mmol/L) & TG (mmol/L) & $\begin{array}{l}\text { HDL } \\
(\mathrm{mmol} / \mathrm{L})\end{array}$ & $\begin{array}{l}\text { VLDL = TG/5 } \\
(\mathrm{mmol} / \mathrm{L})\end{array}$ & $\begin{array}{l}\text { LD=TC-VLDL - } \\
\text { HDL(mmol/L) }\end{array}$ \\
\hline Normal control & $2.200 \pm 0.212$ & $1.240 \pm 0.114$ & $1.500 \pm 0.173$ & $0.248 \pm 0.023$ & $0.452 \pm 0.353$ \\
\hline $\begin{array}{l}\text { Hyperlipidemic } \\
\text { untreated control }\end{array}$ & $4.180 \pm 0.098$ & $4.300 \pm 0.141$ & $0.758 \pm 0.325$ & $0.860 \pm 0.032$ & $2.562 \pm 0.228$ \\
\hline $\begin{array}{l}\text { Atorvastatin } 10 \\
\mathrm{mg} / \mathrm{kg} \text { bw }\end{array}$ & $\begin{array}{l}2.360 \pm 0.167 \\
(43.5 \%)\end{array}$ & $\begin{array}{l}1.140 \pm 0.207 \\
(73.5 \%)\end{array}$ & $\begin{array}{l}1.280 \pm 0.130 \\
(68.7 \%)\end{array}$ & $\begin{array}{l}0.228 \pm 0.041 \\
(73.5 \%)\end{array}$ & $\begin{array}{l}0.852 \pm 0.058 \\
(66.8 \%)\end{array}$ \\
\hline AQE $200 \mathrm{mg} / \mathrm{Kg}$ bw & $\begin{array}{l}2.680 \pm 0.192 \\
(35.9 \%)\end{array}$ & $\begin{array}{l}1.620 \pm 0.164 \\
(62.3 \%)\end{array}$ & $\begin{array}{l}1.420 \pm 0.130 \\
(87.3 \%)\end{array}$ & $\begin{array}{l}0.324 \pm 0.033 \\
(62.2 \%)\end{array}$ & $\begin{array}{l}0.936 \pm 0.129 \\
(63.5 \%)\end{array}$ \\
\hline $\mathrm{AQE} 100 \mathrm{mg} / \mathrm{Kg}$ bw & $\begin{array}{l}3.025 \pm 0.096^{\mathrm{a}, \mathrm{b}} \\
(27.6 \%)\end{array}$ & $\begin{array}{l}1.625 \pm 0.25 \\
(62.2 \%)\end{array}$ & $\begin{array}{l}0.825 \pm 0.171 \\
(8.8 \%)\end{array}$ & $\begin{array}{l}0.325 \pm 0.034 \\
(62.2 \%)\end{array}$ & $\begin{array}{l}1.875 \pm 0.170^{a, b} \\
(26.8 \%)\end{array}$ \\
\hline CHE $200 \mathrm{mg} / \mathrm{Kg}$ bw & $\begin{array}{l}2.450 \pm 0.100 \\
(41.4 \%)\end{array}$ & $\begin{array}{l}1.375 \pm 0.075 \\
(68.0 \%)\end{array}$ & $\begin{array}{l}1.625 \pm 0.206 \\
(114.4 \%)\end{array}$ & $\begin{array}{l}0.275 \pm 0.010 \\
(68.0 \%)\end{array}$ & $\begin{array}{l}0.550 \pm 0.390^{\mathrm{a}} \\
(78.5 \%)\end{array}$ \\
\hline CHE $100 \mathrm{mg} / \mathrm{Kg}$ bw & $\begin{array}{l}2.575 \pm 0.096 \\
(38.4 \%)\end{array}$ & $\begin{array}{l}1.525 \pm 0.189 \\
(64.5 \%)\end{array}$ & $\begin{array}{l}1.050 \pm 0.129 \\
(38.5 \%)\end{array}$ & $\begin{array}{l}0.305 \pm 0.038 \\
(64.5 \%)\end{array}$ & $\begin{array}{l}1.220 \pm 0.016^{\mathrm{a}} \\
(52.4 \%)\end{array}$ \\
\hline
\end{tabular}

Note: $\mathrm{AQE}$ and $\mathrm{CHE}$ are the hydrophilic $70 \%$ aqueous ethanol and lipophilic chloroform extract respectively of $P$. tuber reguim sclerotia. All the treated groups exhibited significant $(\mathrm{p}<0.05)$ ameliorating effect compared to the Triton- $\mathrm{x} 100$ induced hyperlipidemic untreated group. ${ }^{\text {a }}$ significantly different $(\mathrm{p}<0.05)$ compared to standard drug atorvastatin,

bignificantly different $(\mathrm{p}<0.05)$ compared to CHE at dose of $100 \mathrm{mg} / \mathrm{kgbw}$. Values in parenthesis are the percentage ameliorating effect

\section{CONCLUSIONS}

This work demonstrated that both aqueous extract (AQE) and chloroform extract (CHE) of Pleurotus tuber-regium possess lipid lowering effect which suggests that the sclerotium has antihyperlipidemic properties. Further investigation is ongoing to isolate in the pure form the anti-hyperlipidemic chemical constituents that could serve as leads in the development of novel and useful drugs for the management of obesity and related complications due to diabetes and cardiovascular ailments.

\section{ACKNOWLEDGEMENTS}

The authors are grateful to Mr Gospel, the Technologist at the animal house of the Department of Experimental Pharmacology and Toxicology, Faculty of Pharmaceutical Sciences, University of Port Harcourt, Nigeria.

\section{REFERENCES}

1. Bertges, L. C., Mourão Jr, C. A., Souza, J. B., \& Cardoso, V. A. C. (2011). Hyperlipidemia induced 
by Triton WR1339 (Tyloxapol) in Wistar rats. Braz J Med Sci Health, 1, 32-34.

2. Omede, A., Atanu, F. O., Suleiman, M. S., Omotoso, O. D., Jegede, R., \& Sheneni, V. D. (2018). Lipid Lowering effect of Vernonia amagdalina leaf extracts on Triton WR 1339induced hyperlipidemia in the rats. The Journal of Pharmacology; 7(3):292-297.

3. Bahmani, M., Mirhoseini, M., Shirzad, H., Sedighi, M., Shahinfard, N., \& Rafieian-Kopaei, M. (2015). A review on promising natural agents effective on hyperlipidemia. Journal of evidencebased complementary \& alternative medicine, 20(3), 228-238.

4. Velagapudi, S., Piemontese, A., Rohrer, L., \& von Eckardstein, A. (2017). VEGF-A regulates subcellular localization of scavenger receptor BI and transcytosis of high density lipoproteins but not low density lipoproteins in aortic endothelial cells. Atherosclerosis, 263, e33.

5. Kim, H. Y., Jeong, D. M., Jung, H. J., Jung, Y. J., Yokozawa, T., \& Choi, J. S. (2008). Hypolipidemic effects of Sophora flavescens and its constituents in poloxamer 407-induced hyperlipidemic and cholesterol-fed rats. Biological and Pharmaceutical Bulletin, 31(1), 73-78.

6. Iyer, D., \& Patil, U. K. (2011): Effect of Evolvulus AlsinoidesL. ethanolic extract and its fraction in experimentally induced hyperlipidemia in rats. Pharmacology online, 1:573-80.

7. Owolabi, O. J., Anaka, O. N., Innih, S. O., \& Jimba, O. (2013). Evaluation of the Antihyperlipidemic Activity of the Aqueous Root Extract of Elaeis gunensis, Jacq (Arecaceae). Nigeria Journal of Natural Product and Medicine. 17.

8. Kourounakis, M., Victoratos, P., Peroulis, N., Stefanou, N., Yiangou, M., \& Lorke, Nehete, J. Y., Bhambar, R. S., Narkhede, M. R., \& Gawali, S. R. (2013). Natural proteins: Sources, isolation, characterization and applications. Pharmacognosy Reviews; 7(14):107-115.

9. Ghori, S. S., Khan, M. R., e Alam, K., \& Abrar, A. H. (2015). Evaluation Of Antihyperlipidemic Activity Of Ethanolic Extact Of Glycosmis Pentaphylla In Hyperlipidemic Wistar Rats. International Journal of Pharma Sciences and Research, 6(2), 288-292.

10. Zoberi, M. H. (1973). Some edible mushrooms from Nigeria. Nigeria field, 388:81-90.

11. Filipic, M., Umek, A., \& Mlinaric, A. (2002). Screening of Basidiomycete mushroom extracts for antigenotoxic and bio-antimutagenic activity. Die Pharmazie, 57(6), 416-420.

12. Hu, S. H., Liang, Z. C., Chia, Y. C., Lien, J. L., Chen, K. S., Lee, M. Y., \& Wang, J. C. (2006). Antihyperlipidemic and antioxidant effects of extracts from Pleurotus citrinopileatus. Journal of agricultural and food chemistry, 54(6), 2103-2110.
13. Ngai, P. H., \& Ng, T. B. (2006). A Hemolysin from the mushroom Pleurotus eryngii. Applied Microbiology Biotechnology. 75:1185-1191.

14. Jong, S. C., Birmingham, J. M., \& Pai, S. H. (1991). Immunomodulatory substances of fungal origin. International Journal of Immunopharmacology. 3:115-122.

15. Oyetayo, O. V. (2011). Medicinal Uses of Mushrooms in Nigeria: Towards Full and Sustainable Exploitation. African Journal of Traditional Complement and Aternative Medicine. 8(3):267-274.

16. Patel, J. S., Setty, S. K., Chakraborty, M., \& Kamath, J. V. (2011). Antihyperlipidemic activity of Medohor Vati in Triton X-100 induced hyperlipidemic rats. International Journal of Pharmaceutical Research Development, 4:125130.

17. Hikmat, S., Tariq, A., Dania, A., Ghassan, S., Ghassan, A. S., Dima, S., Reena, A. K., \& Yusuf, A. (2017). Synthesis and invivo anthihyperlipidemic activity of novel nbenzoylphenyl-2-furamide derivatives in Wistar rats. Tropical Journal of Pharmaceutical Research, 16(1):193-201.

18. Schurr, P. E., Schultz, J. R., Parkinson, T. M., \& Sodipo, O. A. (1972). Triton induced hyperlipidaemia in rats as an animal model for screening hypolipidemic drugs. Lipids, 7:69-74.

19. Lorke, D. (1983). A New Approach to Acute Toxicity Testing. Archives Toxicology. 54:257287.

20. Kothiyal, P., \& Gupta, A. K. (2011). Anthihyperlipidemic activity of aqueous and ethanolic extracts of fruits of Kigelia Africana (Lam.) Benth. In Triton X-100 induced hyperlipidemic rats, Pharmacology online, 3:386396.

21. Houghton, P. J., \& Raman, A. (1999). Laboratory handbook for the fractionation of natural extracts. London: Chapman and Hall Ltd.

22. Harbourne, J. B. (1973). Phytochemical methods. London: Chapman and Hall Ltd.

23. Venkatesham, A., Vasu, K., Srinivas, P., Rajyalakshmi, G., \& Jagan, M. K. (2009). Antihyperlipidemic activity of methanolic extract of Garlic (Allium sativum L.) in Triton X-100 induced hyperlipidemic rats. Journal of Pharmaceutical Research, 2:777-780.

24. Afieroho, O. E., \& Ugoeze, K. C. (2014). Gas chromatography-mass spectroscopic (GC-MS) analysis of n-hexane extract of Lentinus tuberregium (Fr) Fr (Polyporaceae) Syn Pleurotus tuber regium Fr sclerotia. Tropical Journal of Pharmaceutical Research, 13(11), 1911-1915.

25. Gil-Ramírez, A., Ruiz-Rodríguez, A., Marín, F. R., Reglero, G., \& Soler-Rivas, C. (2014). Effect of ergosterol-enriched extracts obtained from Agaricus bisporus on cholesterol absorption using 
an in vitro digestion model. Journal of functional foods, 11, 589-597.

26. He, W. S., Cui, D., Li, L., Rui, J., \& Tong, L. T. (2020). Plasma triacylglycerol-reducing activity of ergosterol linolenate is associated with inhibition of intestinal lipid absorption. Journal of Functional Foods, 64(103686):1-7.

27. Nehete, J. Y., Bhambar, R. S., Narkhede, M. R., \& Gawali, S. R. (2013). Natural proteins: Sources, isolation,

characterization

and

applications. Pharmacognosy reviews, 7(14), 107.

28. Gil-Ramírez, A., Caz, V., Martin-Hernandez, R., Marín, F. R., Largo, C., Rodríguez-Casado, A., ... \& Soler-Rivas, C. (2016). Modulation of cholesterol-related gene expression by ergosterol and ergosterol-enriched extracts obtained from Agaricus bisporus. European journal of nutrition, 55(3), 1041-1057. 